\title{
6 \\ On the Luck Objection to Libertarianism
}

David Widerker and Ira M. Schnall

\section{Introduction}

Libertarians typically believe that we are morally responsible for the decisions (or choices) we make only if those decisions are free, and our decisions are free only if they are neither deterministically caused nor nomically necessitated by antecedent events. A well-known objection to their view is what we may call 'The Randomness Objection':

(RO) A decision (choice) that is not causally determined by antecedent events is a random occurrence and, therefore, cannot be regarded as a free action.

The standard libertarian response to this objection is that it begs the question against the libertarian position. The objection assumes that every event in the universe is either causally determined or else is a random occurrence, thus equating the absence of causal determination with randomness. The libertarian rejects this assumption. He maintains that if an event is not causally determined, then: either it happens randomly; or, in case it is (or involves) a decision or a choice of an agent, it is a free action, an exercise of free agency. For a libertarian, indeterminism per se neither undermines free agency, nor renders an action free. Rather, it is a condition that makes the performance of free action possible, a condition that makes room, or provides the opportunity, for the exercise of free agency.

Note that the libertarian's answer is not dogmatic. It is supported by our everyday experience. Suppose I deliberate whether to keep a promise I made, and ultimately decide to keep it. I do not experience the decision I make as something that happens to me out of the blue, or at 
random - the way we experience a thought that pops into our head unbidden, or a desire we sometimes find ourselves with. Rather, I experience my deciding to keep the promise as something I do; as something I do directly, as opposed to doing it by performing another act; and furthermore, as something that I believe I had control over, in the sense that it was up to me whether to decide to keep the promise or not. Whether or not the way we experience making a decision is veridical, attention to it can give us an understanding of what libertarians mean by 'agency' and 'free action'.

Recently there have been a number of attempts by philosophers to discredit libertarianism via an argument which purports to establish a conclusion similar to RO:

If an agent $\mathrm{S}$ is faced with a choice between performing two alternative actions $\mathrm{A}$ and $\mathrm{B}$, and it is causally undetermined whether $\mathrm{S}$ will decide to A or decide to B up until the time at which $S$ makes the decision, then which decision the agent ultimately makes is a matter of luck, meaning that the agent does not have control over which decision he makes.

The argument for this conclusion has been dubbed 'the Argument from Luck' or 'the Luck Objection' against libertarianism - henceforth LO. In this paper, we wish to examine some versions of LO as reflected in the works of Alfred Mele (2006a, 2013), Neil Levy (2011), and Peter van Inwagen $(2000,2011)$. We argue that libertarians have nothing to fear from LO. Deep down the objection reflects a failure, on the part of its proponents, really to come to grips with the libertarian position.

Though LO applies to most forms of libertarianism, we shall be concerned with defending one specific libertarian position whose main tenets are described below:

(a) An agent $\mathrm{S}$ who freely performs an act $\mathrm{A}$ at time $\mathrm{t}$, acts of his own accord in the sense that his act is neither caused nor nomically necessitated by events occurring prior to $t$.

(b) Every free act (indeed any act) is either a simple mental act, such as volition, decision, or an agent's actively forming an intention to A (as opposed his acquiring an intention passively); or else it is a complex act, consisting in a simple mental act standing in a certain relation to other events (e.g., S's act of raising his arm consists in a simple mental act causing the event of Smith's hand rising). A simple mental act, for example, a decision to A is simple in the sense that 
it does not contain another act as a part, and in that it does not consist in a simple mental act causing another event (Ginet 1990: 11). Crucial to this notion of an act is the idea that what makes a certain event an act is something that is intrinsic to it, and not the way the event is caused, as a causal theory of action would maintain (Ginet 1990: chap. 1). Note that a mental act such as a decision can also occur in a deterministic world, although there it would not count as a free act.

(c) Agents capable of performing free acts have the capacity to engage in practical reasoning and to act for the reasons they have.

(d) When an agent acts freely for a reason, for example, when he travels to New York because he wants to see his mother, the explanatory relation between the agent's act and the reason for which he acts is not causal, but teleological. ${ }^{1}$ The agent performs the act in order to attain a certain goal (in order to see his mother), viewing the act as a means to realizing that goal.

(e) Finally, we shall assume that:

(LF) If an agent freely performs an act $\mathrm{A}$ at time $\mathrm{t}$, then until $\mathrm{t}$, it was within the agent's power to act otherwise at $t$, or to avoid acting at $\mathrm{t}$ as he did. ${ }^{2}$ (LF stands for 'Leeway-Freedom'.)

This account of a free action is an account of a directly free action ${ }^{3}-$ as opposed to an indirectly (or derivatively) free action, which is 'free' only in the sense that it is caused or nomically determined by one or more free actions. We shall dub the brand of libertarianism geared to this notion of a directly free action 'Leeway-Libertarianism', or 'L-libertarianism', or for short LL.

In general, we may distinguish three kinds of libertarian theories: (1) Non-causal libertarianism (NCL), (2) Agent-causal libertarianism (ACL), and (3) Event-causal libertarianism (ECL). According to NCL, the explanatory relation between the agent's decision and the reason for it is not causal, but teleological. The agent decides to act in a certain way in order to attain a certain goal, viewing the decision as a means to realizing that goal. The reason explains the decision in the sense that, being aware of the reason, the agent, in an intrinsically intentional act of intention-formation, forms an intention the content of which reflects the very goals presented in that reason - decides to travel to New York in order to see his mother. ${ }^{4}$ According to ACL, an agent's freely performing an act A always begins with the agent's causing an intention to A, where the causing itself is neither caused nor nomically determined. The causal relation that obtains between the agent and the intention to $\mathrm{A}$, usually 
referred to as 'agent-causation', is sui generis, in the sense that it cannot be reduced to event-event causation or to nomic regularity. ${ }^{5}$ By contrast, proponents of ECL try to give an account of free action without committing themselves to such a special causal relation as agent-causation. According to ECL, a free act performed for a reason is indeterministically caused by the reason. ${ }^{6}$

The account of free action we favor, LL, is a species of Non-causal libertarianism. It differs from ACL in that it does not require that to perform a free act, the agent must (agent) cause the act. And it differs from ECL in that it does not require that in order for a free act to be done for a reason, the act must be indeterministically caused by the reason. On LL, the agent has the power to perform a simple mental action (a decision or an active formation of an intention) directly, without having to cause it in any way. Thus LL makes no ontological commitment to any recherché type of causal relation, such as agent-causation. In other respects, however, LL does not differ much from an ACL-theory of a free action. ${ }^{7}$ We are now ready to consider the Luck Objection to libertarianism.

\section{Mele's version of the luck objection}

Alfred Mele (2006a: 7-8) presents his version of the luck objection (LO) in terms of a fable: Diana, a goddess who is a libertarian and who lives in an indeterministic world, wants to create rational, free human agents. Being a libertarian, Diana believes that free decisions cannot be deterministically caused, not even by an all-things-considered best judgment that it would be best to A straightaway; and that agents should be able to make free decisions based on such judgments. Qua L-libertarian, Diana also believes that:

(LF) If an agent freely performs an act A at time $t$, he could have freely performed some alternative act at $\mathrm{t}^{8}$

So Diana designs her agents in such a way that, even though they have just made an all-things-considered best judgment, they may still decide to act contrary to it.

Upon further reflection, however, Diana begins to worry that her design does not really accommodate her goal of creating rational, free agents. To appreciate her worry, let us suppose that Joe, one of the agents Diana has created, performs a free action at $t$, say a decision to A, which is in accordance with Joe's best judgment about what to do in the circumstances. Since the decision is a free action, it follows, given LF, that Joe 
could have freely done otherwise; or stating this in terms of possible worlds, it follows that there is a possible world $\mathrm{W}$ which shares its laws of nature and its past up until (and not including) $t$ with the real world, in which Joe freely acts otherwise. Diana suspects that the difference between Joe's acting in W contrary to his better judgment and his acting in accordance with it in the actual world is just a matter of luck. After all, the two worlds do not diverge before $t$, which means that the difference in Joe's behavior at $t$ in the two worlds lacks an explanation in terms of what happens in them before $t$. But if the difference in Joe's behavior at $t$ in the two worlds cannot be explained in terms of what happens in them before $t$, then the difference between them, Mele claims, is just a matter of luck. ${ }^{9}$ Hence, the decision Joe makes in $\mathrm{W}$ must be a matter of luck, which implies that Joe does not have control over the decision he makes in $\mathrm{W}$, that he cannot be deemed morally responsible for that decision, and that that decision cannot be regarded as a free action.

But if so, then Joe's decision in the actual world also cannot be regarded as a free action, after all (Mele 2006a: 8).

Mele's next move is to argue that Diana's worry generalizes, meaning that the above argument applies to all cases in which an agent makes a L-libertarian free decision, even those where the agent's decision to $\mathrm{A}$ is not preceded or accompanied by a pertinent best judgment (2006a: 9).

It may useful at this point, to state Mele's generalized argument schematically:

(1) Suppose that at time $t$, an agent $S$ makes a (directly) free decision to A (Ass.).

(2) If an agent $\mathrm{S}$ freely decides at time $\mathrm{t}$ to $\mathrm{A}$, he could have freely performed some alternative act at $t$ (by LF).

(3) Hence, $\mathrm{S}$ could have freely performed some alternative act at $\mathrm{t}$ (by 1 and 2).

(4) If $\mathrm{S}$ could have freely performed some alternative act at $\mathrm{t}$, then there is a possible world $\mathrm{W}$ which shares its laws of nature and its past up until (and not including) $t$ with the real world, in which $S$ freely acts otherwise at $\mathrm{t}$ (Ass.).

(5) There is a possible world $\mathrm{W}$ which shares its laws of nature and its past up until (and not including) $t$ with the real world, in which $S$ freely acts otherwise at $\mathrm{t}$ (by 3,4 ).

(6) The difference in S's behavior at $t$ between the two worlds - that in the real world, $\mathrm{S}$ decides at $\mathrm{t}$ to $\mathrm{A}$, whereas in $\mathrm{W}, \mathrm{S}$ acts otherwise at $t$ - cannot be explained in terms of what happens in those worlds before $t$ (Ass.). 
Mele calls this difference between the actual world and W, 'the cross-world difference between the two worlds with regard to how $S$ acts at $t^{\prime}$ (2006a: 54).

(7) If the cross-world difference between $\mathrm{W}$ and the actual world with regard to how $S$ acts at $t$ cannot be explained in terms of what happens in both these worlds before $t$, then that difference is just a matter of luck (Ass.).

(8) The cross-world difference between $\mathrm{W}$ and the actual world with regard to the decision $S$ makes at $t$ is just a matter of luck (by 6,7 ).

(9) Luck entails lack of control (Ass.). ${ }^{10}$

(10) S lacks control over the decision he makes at $t$ in $\mathrm{W}$, which means that in $\mathrm{W}$, he does not act freely at t. ${ }^{11}$

(11) S could not have freely performed some alternative act at $\mathrm{t}$ (by 4 , 10).

(12) But the conjunction of (1) and (11) contradicts (2).

Since we obtained a result that contradicts LF, the conclusion we are expected to draw from it is that LF needs to be rejected. ${ }^{12,13}$

In a nutshell, Mele's worry about L-libertarianism is that its notion of a free act is incoherent. It is incoherent, since necessarily, whenever an agent acts freely in a L-Libertarian sense, there is a cross-world difference that cannot be explained, and is therefore just a matter of luck; and this result apparently leads the L-libertarian into an inconsistency. ${ }^{14}$

\subsection{Mele's argument assessed}

To properly assess Mele's argument against LF, it is important to have a clear understanding of: (a) what it means for a cross-world difference not to have an explanation, and (b) why the lack of such an explanation is supposed to pose a serious problem for the L-libertarian. We might begin by asking what it would be for the cross-world difference to have an explanation, and therefore not be just a matter of luck. We may say that if $\mathrm{S}$ does $\mathrm{A}$ at $\mathrm{t}$ in world $\mathrm{W} 1$, and $\mathrm{S}$ does $\mathrm{B}$ (incompatible with $\mathrm{A}$ ) at $t$ in $\mathrm{W} 2$, then this cross-world difference between $\mathrm{W} 1$ and $\mathrm{W} 2$ has an explanation if and only if: (i) there is an explanation (in terms of what transpired prior to $t$ - henceforth understood) of why $\mathrm{S}$ does $\mathrm{A}$ at $\mathrm{t}$ in $\mathrm{W} 1$ and (ii) there is also an explanation of why $\mathrm{S}$ does $\mathrm{B}$ at $\mathrm{t}$ in $\mathrm{W} 2$. This implies that when the cross-world difference between W1 and W2 lacks an explanation, then either S's doing A at $\mathrm{t}$ in W1 lacks an explanation or S's doing B at t in W2 lacks an explanation. Hence, step (6) in Mele's argument is equivalent to the disjunction (6a) Either the decision that 
$\mathrm{S}$ makes at $\mathrm{t}$ in the real world $\mathrm{R}$ lacks an explanation in terms of the facts that obtain before $t$ in $\mathrm{R}$, or the decision $\mathrm{S}$ makes at $\mathrm{t}$ in $\mathrm{W}$ lacks an explanation in terms of the facts that obtain before $t$ in $W$. But now how exactly is (6a) supposed to generate a problem for the L-libertarian? Of course, if following Mele, one assumes that an unexplained crossworld difference entails luck (7), and that luck entails lack of control (9), one soon arrives (via 6a) at the conclusion that (10) S's decision to $\mathrm{A}$ in $\mathrm{W}$ is not a free action, ${ }^{15}$ which implies that $\mathrm{S}$ 's decision to $\mathrm{A}$ in the actual world is also not a free action, and that therefore, LF needs to be rejected.

However, an L-libertarian would object to this way of completing the argument against his position. He would point out that the joint assumption of (7) and (9) commits one to assuming a conceptual link between lack of explanation and lack of control; and as Mele offers no argument for this assumption, the L-libertarian would argue that he has no good reason to accept it. ${ }^{16}$ Furthermore, there seem to be counterexamples to it. Consider a situation in which $S$ is torn between his desire to steal an expensive necklace he sees in a jewellery store, and his desire, for moral reasons, to refrain from stealing it. Ultimately, $\mathrm{S}$ decides to steal the necklace, and steals it. Assume further that it was within S's power, in the L-libertarian sense, to refrain from the decision he made, that is, that there is a possible world $\mathrm{W}$, indistinguishable from the actual world up until $t$, in which $\mathrm{S}$ decides not to steal the necklace at $\mathrm{t}$. In this situation, there is a cross-world difference that lacks an explanation. And yet, intuitively it is not the case that $\mathrm{S}$ was lacking control over the decision he made. After all, the decision did not seem to him as something that occurred to him out of the blue. Rather, he experienced the decision as something he made, something he made deliberately, and made in the belief that it was within his power to decide otherwise. Mele, the L-libertarian might claim, has not given him a good reason to think that belief is false. ${ }^{17}$

Mele seems to be aware of this reply. However, he insists that luck remains a problem for LL for the reasons that he stated in his argument against LL. He says:

Are we to believe that the pertinent cross-world difference is not just a matter of luck? If so, why?... Why should we not believe that the difference is just a matter of luck and that, because it is, the agent is not morally responsible for his decision and does not make it freely. (2006a: 69) 
We find this reply by Mele puzzling. We see in it an unyielding resistance on Mele's part to countenance the notion of a libertarian free act, without showing clearly that this notion is incoherent.

Other passages suggest that what Mele is demanding of the L-libertarian is a reductive account of a free act (in the L-libertarian sense), as opposed to an event whose occurrence is a matter of luck. To us such a demand seems inappropriate.

\subsection{Mele's latest argument against LL}

In a recent article (Mele 2013), Mele reformulates his objection to LL, referring to it as 'the continuation problem'. In that restatement, Mele studiously avoids using the notion of luck, pointing out that his earlier use of this notion led critics to focus on issues that are irrelevant to the problem that he was raising. The problem for LL, Mele argues, can be brought out the by the following example:

Bob has been charged with the task of flipping a coin at exactly 12:00 noon to begin a football game. Carl, a gambler, has bet heavily that the coin flip will not occur exactly at noon, and has tried to bribe Bob to delay the coin flip. Bob is tempted to accept the bribe and do as Carl wants, but he wants to do the right thing. So he tries with all his might to resist the temptation, and to decide to flip the coin at exactly 12:00. But despite his very best efforts, at noon he decides to delay the coin flip; he pretends to be looking for the coin, and finally flips it at 12:02, thus enabling Carl to win his bet. (2013: 238-9)

According to L-libertarianism, Bob's is a directly free action, and Bob is morally responsible (blameworthy) for it, since he is morally competent, and there is a possible continuation of all that transpired before noon, in which Bob decides at noon to flip the coin forthwith. Mele finds this strongly counterintuitive. He says,

That things can turn out so differently at $t$ (morally or evaluatively speaking) despite the fact that the worlds share the same past up to $\mathrm{t}$ and the same laws of nature suggests.... that Bob lacks sufficient control over whether he makes the bad decision or does something else instead to be basically morally responsible for the decision he actually makes. After all, in doing his best, Bob did the best he could do to maximize the probability (before $t$ ) that he would decide to do the right thing, and, even so, he decided to cheat. (2013: 240) 
The new point that Mele seems to be making here is that according to LL, no matter how hard the agent tries to do the right thing, he cannot guarantee that he will do the right thing, and so if it turns out that he does the wrong thing, then how can we blame him for so doing?

Mele is careful to point out that he does not view the above as an argument for the incoherence or falsity of LL. Rather, given that, according to LL, Bob's decision is a directly free action, he is challenging the proponent of LL to explain how Bob can be said to exercise sufficient control over his action to be morally responsible for it. Despite this disclaimer, there certainly is an implied argument against LL in what Mele says: that is, the worry he raises is intended to strengthen the claim that agents who act freely in the LL sense, lack sufficient control to be morally responsible for their actions. The question is whether the L-libertarian can allay this worry. We believe he can.

First, note that Mele's portrayal of Bob's situation as expressed in the quotation above is misleading. It suggests that after all the efforts Bob made (before t) to make the moral decision to flip the coin at noon efforts that may have resulted in his forming an all-things-considered judgment that it would be best for him to act morally - Bob's task qua agent ended, and he had to watch passively (at $t$ ) to see whether his efforts would be successful. In this way, the reader is led to believe that Bob did not have sufficient control over his decision at $t$.

Obviously, the L-libertarian would not agree with this description of Bob's situation. On his view, what happened was that at $t$, Bob, despite his earlier efforts, decided on his own to delay the flip, either because he changed his mind regarding what would be best for him to do, or because he acted akratically, succumbing to temptation. But in either case, Bob exercised sufficient control over his decision to delay the flip to be regarded morally responsible for it, since he actively made it, and it was within his power to decide otherwise. Mele has not provided a good reason to think otherwise, and so the L-libertarian is within his epistemic rights to continue to hold on to his theory.

We, therefore, conclude that Mele's version of the Luck Argument fails to refute LL.

\section{Levy's version of the luck objection}

Neil Levy (2011: chap. 3) presents another version of the Luck objection (LO) to libertarianism. Although Levy provides an elaborate presentation 
of how LO applies to all forms of libertarianism, his objection to LL boils down to the following two claims:

(LV1) In order for a decision or choice to be free, in the sense of 'free' relevant to moral responsibility, it is required that there be a contrastive explanation of it.

(LV2) An L-libertarian directly free action cannot be given a contrastive explanation, and therefore, does not satisfy the requirement stated in LV1 (2011: 42-3).

What is Levy's argument for LV1? Levy assumes that when it comes to giving an account of moral responsibility, we are primarily interested in giving such an account for an agent's choices and decisions, since these constitute the loci of human agency. For Levy, the relevant notion that a theory of moral responsibility ought to focus upon is:

S's being (directly) morally responsible for making choice C1, rather than making choice $\mathrm{C} 2$, where $\mathrm{C} 2$ has a moral valence that conflicts with that of $\mathrm{C} 1$.

By 'moral valence of an action' he understands the action's moral value. An action has a positive valence if it is morally good, and a negative valence if it is morally bad; a pair of alternative actions have conflicting moral valences just in case one of them is either good or bad and the other is either of the opposite valence or morally neutral. Hence, an agent's being morally responsible for a choice implies his being responsible for making a choice between two actions with conflicting moral valences. For example, to regard an agent as morally responsible for choosing to steal an expensive necklace is to regard him as (directly) morally responsible for choosing to steal the necklace rather than choosing not to steal it. From this, Levy infers that an adequate account of moral responsibility must have the resources to explain an agent's choice contrastively. It must allow us to explain, for example, why, given the options that confronted the agent, he chose to steal the necklace rather than choosing not to do so. He says:

The fact that direct moral responsibility is moral responsibility for a choice between options of conflicting moral valence entails that an adequate account of moral responsibility must have the resources to explain choices contrastively. It is not enough to offer an explanation of why the agent chose as she did, if we leave unexplained why 
she chose one option and not another (of a conflicting valence). The contrastive explanation must therefore be of the decision: it must explain why, given the options that confronted the agent, she chose that particular one. Because it must explain this fact, the contrastive explanation must cite facts that obtained at the time at which the options were (metaphysically or epistemically) open to the agent. (2011: 43)

\subsection{Levy's argument assessed}

We find Levy's argument (for LV1) unconvincing. We may agree with Levy that an adequate account of an agent's S's moral responsibility for his choice (decision) C1 must be an account of why:

(a) $\mathrm{S}$ is morally responsible for making choice $\mathrm{C} 1$ rather than choice $\mathrm{C} 2$,

where $\mathrm{C} 1$ and $\mathrm{C} 2$ are the options (with conflicting valences) the agent was confronted with. But it does not follow from this that such an account must explain why,

(b) $\mathrm{S}$ made choice $\mathrm{C} 1$ rather than choice $\mathrm{C} 2$.

Obviously, (a) and (b) are two quite different facts.

To see this more clearly, let's again employ the example we used earlier of an agent $\mathrm{S}$ who, being torn between his selfish desire to steal an expensive necklace, and his desire to refrain from doing so for moral reasons, ultimately makes the morally wrong choice. Note that, even if we knew that there was no contrastive explanation of why $S$ chose to steal the necklace, we would still be justified in holding $\mathrm{S}$ morally blameworthy for stealing the necklace. We would be justified in this belief, provided we would know (or would be justified in believing) that when choosing to steal the necklace, $\mathrm{S}$ was aware that he was acting in a morally wrong way, and that he could have refrained from doing so.

What this example brings out is that in determining whether a person is morally blameworthy for choosing to act immorally, we need not be concerned with the question of whether there was a contrastive explanation of his choice. This strongly indicates that one may be blameworthy for choosing to act immorally, even if there is no contrastive explanation of why he chose the way he did. Being blameworthy seems to hinge on such factors as whether, when deciding how to act, the agent was aware of the moral significance of the options before him, whether he was coerced or compelled to make the decision he made, etc. These factors 
may obtain even if there is no contrastive explanation of why made the choice he did, rather than an alternative choice. We, therefore, do not think Levy's version of LO is successful against L-libertarianism.

\subsection{Another objection}

In the course of criticizing various libertarian accounts of free action, Levy raises what can be regarded as another objection to LL. He claims that LL leads to implausible consequences when applied to actions for which there exists a contrastive reasons-explanation. ${ }^{18}$ This is a weaker claim than the charge we considered earlier, involving LV1 and LV2. Yet, if true, it, too, would pose a problem for a L-libertarian account of free action; for often we do perform free actions for which a contrastive explanation can be given. Levy's objection may be described as follows.

Consider a situation where $\mathrm{S}$ has better reasons to do A than to do B, and ultimately does A. To use Levy's own example, suppose that Jane has better reasons to vacation in Hawaii than in Colorado and ultimately decides to vacation in Hawaii. ${ }^{19}$ Levy claims that if Jane's ultimate decision were an L-libertarian free action, one that it was up to Jane whether to perform it or not, this fact would manifest itself in one of two ways: Jane might either (a) put her weight behind the option that she prefers - that of vacating in Hawaii - and act for that reason, or (b) she might select an option that was, for her, less rational. Both these alternatives, Levy argues, are problematic. On (a), Jane's role, as agent, turns out to be 'idle' since, by putting her weight behind the action selected by her reasons, she merely endorses the action that is 'selected event-causally by the agent's reasons' (our emphasis). Hence, qua agent, she does not contribute anything to determining, or controlling, which action she performs. Option (b) is problematic as well, since, were Jane to choose to vacation in Colorado her action would lack a contrastive explanation, and hence, according to LV1, would not count as a free action (2011: 68-9).

Of the two horns of the dilemma that Levy describes, it is the first which threatens the L-libertarian position. The second horn is easily rebutted, since it makes use of an assumption which we found problematic: namely, LV1. So what about the first horn? To see what's wrong with it, let us ask: what does Levy mean by saying that the action Jane is putting her weight behind - her choosing to vacation in Hawaii - is 'selected event-causally' by the agent's reasons? If he thinks that the action is brought about event-causally by the agent's reasons either deterministically or indeterministically, then his assumption is inconsistent with L-libertarianism, according to which an agent's free act is neither caused nor nomically necessitated. ${ }^{20}$ On the other hand, if he simply means 
that Jane endorses the action which her reasons have already selected as the better alternative (in the circumstances), then this does not entail that, in doing so, Jane does not contribute anything to controlling/determining which action she performs. After all, Jane could have decided to vacation in Colorado (or she could have decided meanwhile to postpone making up her mind as to where she wishes to vacation); had she done so, she would not have decided to vacation in Hawaii.

\section{Van Inwagen's version of the luck objection}

Peter van Inwagen (2000) advanced the discussion of LO by introducing the inter-related concepts of rollbacks and replays. Applied to L-libertarianism van Inwagen's objection can be expressed as follows: Suppose that $\mathrm{S}$ does $\mathrm{A}$ at $\mathrm{t}$, and that this is a directly free act in the L-libertarian sense. This implies that, before $t$ it was undetermined whether $\mathrm{S}$ would do $\mathrm{A}$ at $\mathrm{t}$. Van Inwagen now asks us to imagine that after $\mathrm{S}$ does $\mathrm{A}$ at $\mathrm{t}$, we somehow roll back to a time before $\mathrm{t}$, and then allow events to unfold again, watching to see whether $S$ will again freely do $A$ at $t$ in the replay. Imagine that we perform the rollback and the replay many times (as in the movie Groundhog Day - except that $\mathrm{S}$ does not remember any of the preceding unfoldings of events). Van Inwagen claims that, since it was undetermined before $t$, whether or not $S$ does $A$ at $t$, we will see, if we watch enough replays, that in some of them $S$ does not do $\mathrm{A}$ at $\mathrm{t}$, and that the ratio of replays in which $\mathrm{S}$ does $\mathrm{A}$ at $\mathrm{t}$ to replays in which $\mathrm{S}$ does not do $\mathrm{A}$ at $\mathrm{t}$ will eventually converge on some value (presumably equal to the probability, given the past before $t$, that $\mathrm{S}$ will do $\mathrm{A}$ at $\mathrm{t}$ ). He infers that, in any given replay, it is purely a matter of chance whether S does $\mathrm{A}$ at $\mathrm{t}$, and moreover that even the first time (in the original 'play') it was purely a matter of chance that S did A at $t$. But, if it is a matter of chance whether $S$ does $A$ at $t$, then whether he does $\mathrm{A}$ at $\mathrm{t}$ is not in S's control, which implies that his doing $\mathrm{A}$ at $\mathrm{t}$ is not a free action (2000: 14-16).

The introduction of replays provides an effective way to picture the alleged anti-libertarian consequences of indetermination. Libertarians have felt relatively comfortable with their position that free actions are undetermined by antecedent conditions. Talk of replays may serve to introduce some discomfort, by making more palpable what being undetermined entails. The idea is that if I realize that were I to relive the relevant time-period several times, I would act differently in different replays without being able explain this fact, then I will get the feeling that what I do is not up to me, and that I am a helpless victim of chance. 


\subsection{Van Inwagen's replay argument assessed}

One way in which the L-libertarian may respond to van Inwagen's argument is by insisting that, in van Inwagen's thought experiment, $\mathrm{S}$ is exercising free agency in doing A at $\mathrm{t}$. S's doing A at $\mathrm{t}$ is not just something that happens to S. S (in the replaying scenario) does not just passively watch to see whether he does $\mathrm{A}$ at $\mathrm{t}$; rather $\mathrm{S}$ acts at $\mathrm{t}$, doing so deliberately. Thus, even if $\mathrm{S}$ does $\mathrm{A}$ at $\mathrm{t}$ in some replays and not in others, the fact remains that what $S$ does in each replay is up to him.

Van Inwagen is aware of this reply, but he contends that, nevertheless, if we could view enough replays we would get the impression that what $\mathrm{S}$ does is merely a matter of chance. ${ }^{21}$

But is that really so? If A is the kind of action that we usually think of as up to the agent, then in each replay that we watch, we will have the impression that it is up to $\mathrm{S}$ whether he does A or whether he does something else instead. We may not be able to predict, as each replay begins, what $S$ will do in that replay, and we may not be able to explain why he does A in one replay whereas he does something else in another replay (at least not in terms of what occurred before $t$ ). But we may very well still have the impression that what $S$ does in every replay is under his control: he is not merely a passive victim of chance. There is a common, intuitive conviction that normally, when we act deliberately, we have control over what we do, in the sense that we could have done otherwise, and (in the absence of a reason to the contrary) we would read this kind of conviction of control into each replay that we view. Van Inwagen has not provided any argument that we would not interpret every replay in this way; nor has he shown that the conviction that the agent is in control is false or unjustified. Given that the conviction is so widespread, the burden of proof is on the critic either to show that we would get the impression that what the agent does in the replays is a matter of chance, or to provide an argument to the effect that the agent is not really in control.

The L-libertarian can also answer van Inwagen in another way. He may question whether the replays van Inwagen posits would fit his description. It is far from clear that it follows, from the fact that S's action is undetermined, that in some replays $\mathrm{S}$ will do $\mathrm{A}$ at $\mathrm{t}$, and in others $\mathrm{S}$ will do something else instead, and that the ratio of the former to the latter will tend to converge on some value. For in each replay, whether $S$ does $\mathrm{A}$ at $\mathrm{t}$ depends on $\mathrm{S}$ : that is, in each replay $\mathrm{S}$ has the power to do $\mathrm{A}$ at $\mathrm{t}$, and $S$ has the power to do something else instead. For all we know, $\mathrm{S}$ may do A in every replay. ${ }^{22}$

Our conclusion is that L-libertarianism is not undermined by van Inwagen's Replay Argument. 


\subsection{Van Inwagen's Promising Argument}

In order to enhance the intuitive appeal of his Replay Argument, whose conclusion was that if it is undetermined whether $\mathrm{S}$ will do A at $\mathrm{t}$, then $\mathrm{S}$ lacks control over whether he will do $\mathrm{A}$ at $\mathrm{t}$, van Inwagen appeals to the following example:

You are a candidate for public office, and I, your best friend, know some discreditable fact about your past that, if made public, would and should cost you the election. I am pulled two ways, one way by the claims of citizenship and the other by the claims of friendship. You know about my situation and beg me not to 'tell'. I know (perhaps God has told me this) that there exist exactly two possible continuations of the present - the actual present, which includes your begging me not to tell and the emotional effect your appeal has had on me -, in one of which I tell all to the press and in the other of which I keep silent; and I know that the objective, 'ground-floor' probability of my 'telling' is 0.43 and that the objective, 'ground-floor' probability of my keeping silent is 0.57 . Am I in a position to promise you that I will keep silent, knowing, as I do, that if there were a million perfect duplicates of me, each placed in a perfect duplicate of my present situation, forty-three percent of them would tell all and fifty-seven percent of them would hold their tongues? I do not see how, in good conscience, I could make this promise. I do not see how I could be in a position to make it. But if I believe that I am able to keep silent, I should, it would seem, regard myself as being in a position to make this promise. What more do I need to regard myself as being in a position to promise to do $\mathrm{X}$ than a belief that I am able to do X? Therefore, in this situation, I should not regard myself as being able to keep silent. (And I cannot see on what grounds third-person observers of my situation could dispute this first-person judgment.) (2000: 17-18)

In a later article (2011), Van Inwagen derives from this example the following argument, which he calls 'The Promising Argument':

[1] If I am able to keep silent, then I am in a position to promise to keep silent;

[2] If it is undetermined whether I shall keep silent, then I am not in a position to promise to keep silent.

Hence, [3] if it is undetermined whether I shall keep silent, I am not able to keep silent ${ }^{23}$ (2011: 477). 
Van Inwagen claims that the above argument generalizes, establishing that, for any action, if it is undetermined, then it is not in the agent's power to perform it (or not to perform it) ${ }^{24}$ If he is right, then he has shown, via the Promising Argument, that L-libertarianism is false.

\subsection{Van Inwagen's Promising Argument assessed}

Van Inwagen reports that Michael Bratman ${ }^{25}$ raised the following objection to the Promising Argument: Even though it is now undetermined whether I will keep silent, nevertheless it might be the case that the very act of promising would determine that I will keep silent later on; and if I am now aware that this is indeed the case, then I am in a position to promise to keep silent. Thus premise [2] of the Promising Argument is false.

Note that one may also raise an objection to premise [1] of the Promising Argument. That is, one may argue that even though one is able to do A, one may nevertheless not be in a position to promise to do A. One may further argue that van Inwagen's own example undermines premise [1]. In the example, since I am undecided (now) whether to keep silent or tell all, it is indeed plausible to say, following van Inwagen, that I am not in a position to promise to keep silent. However, the reason for this need not be that I am not able to keep silent, or that it is not in my power to do so, due to indeterminism. Intuitively, it may very well be in my power to keep silent; rather, the reason why I am not in a position to promise to keep silent is that I am not willing to make such a promise.

Compare this to a case where I am undecided between voting for candidate $\mathrm{X}$ and voting for candidate $\mathrm{Y}$ in an upcoming election, and a friend of mine asks me to promise to vote for X. I am not in a position to promise such a thing, but not because it is not in my power to vote for $\mathrm{X}$; rather, though it may very well be in my power to vote for $\mathrm{X}$, nevertheless I simply haven't made up my mind as to whom to vote for, so I am not prepared, or willing, to commit myself to vote for X by promising to do so.

\subsection{Van Inwagen's modified version of the Promising Argument}

In order to avoid Bratman's objection, van Inwagen (2011) emends his example to include the stipulation that I believe that even if I promise to do as my friend asks (in the emended example, to lie when questioned about his behavior), nevertheless it remains undetermined whether I will keep that promise when the time comes. Also, in the emended version, there is no mention of being undecided, and no mention of the relative probabilities of lying and telling the truth. All I know, in the 
revised version, is that even if I promise to lie, it will remain undetermined whether I will lie or tell the truth, and that therefore, some of my duplicates would lie, and some would tell the truth; this is supposed to be enough to make me feel that I am not in a position to promise to lie (2011: 478). We may summarize the argument implicit in the emended example as follows:

[1a] If it is now in my power to lie tomorrow, then I am in a position to promise (now) to lie tomorrow.

[2a] If it will be undetermined tomorrow whether I will lie, even if I now promise to lie tomorrow, then I am not in a position to promise now to lie tomorrow.

Hence, [3a] If it will be undetermined tomorrow whether I will lie (even if I promise to lie), then it is not now in my power to lie tomorrow.

Van Inwagen acknowledges that the generalization of [3a] is somewhat weaker than the generalization of the original [3]. But he notes that it is still strong enough to entail something that most libertarians would want to deny: namely, that if it will be undetermined at $t$ whether $S$ does $\mathrm{A}$ at $\mathrm{t}$, and nothing $\mathrm{S}$ can do between now and $\mathrm{t}$ can alter that fact, then as of now, it is not in S's power to do A and it is not in S's power to do otherwise. ${ }^{26}$

\subsection{The L-libertarian response to the modified Promising Argument}

Again, we think that a L-libertarian can adequately respond to this objection. The simplest way for him to do so is to reject premise [2a]. He may point out that in van Inwagen's modified example (as opposed to the original example), I may very well not be conflicted, and may believe that it would be all right for me to lie for my friend. And if I do think that it would be all right for me to lie, then intuitively I am in a position to promise now to lie tomorrow, and this despite the fact that whether I will lie or tell the truth is, and will remain, undetermined. That is, the mere fact that it is undetermined whether I will keep the promise does not imply that I am not in a position to make the promise. After all, intuitively, any promise I make involves the possibility that at the moment that I am to carry it out, I will simply decide, perhaps on a whim, not to keep it. That is, the institution of promising has built into it the recognition that when the time comes to carry out the promise, it will be in the promiser's power to break the promise. Yet this recognition does not undermine the practice of promising. Thus, premise [2a] 
of van Inwagen's improved version of the Promising Argument is false, and therefore the L-libertarian is free to deny the conclusion [3a], as well as its generalization. ${ }^{27}$

Before concluding this section, we would like to draw attention to a claim van Inwagen makes in his presentation of his revised Promising Argument that brings into focus the core of the issue between L-libertarians and proponents of LO. He claims that the revised Promising Example is analogous to the following case:

Suppose I believe that when I try to start my car, it will at that moment be undetermined whether it will start...then I should regard myself as not being in a position to promise someone a ride. (2011: 478)

There seems to be a relevant, fundamental distinction to be made between the indeterminacy of my car's starting and the indeterminacy of my lying tomorrow. Intuitively, whether my car will start when I try to start it is purely a matter of chance; the indeterminacy in this case is in the physical world, and in the physical world, absence of a determining cause amounts to mere chance, or randomness. But in the promising case, what is undetermined is what I, as an agent, am going to do actively and deliberately. In such cases, the absence of a determining cause leaves room for free agency - I can, so to speak, step into the 'gap' in the causal chain and make things happen as I see fit at the time. This is precisely the distinction that is at the heart of the debate over the Luck Objection (LO) and L-libertarianism. Proponents of LO either overlook the distinction, claiming that wherever there is indeterminacy there is only randomness, or else challenge the L-libertarianism to give an 'account' of how undetermined agency differs from randomness. ${ }^{28}$

\section{Conclusion}

We have examined several versions of the luck objection (LO), and we have shown how a Leeway-libertarian can respond to each. There is a common theme running through all the versions of LO. The target of the objection is the L-libertarian requirement that in order for an action to be directly free, the action must have been undetermined, and it must have been within the agent's power to have acted otherwise. Thus, according to this requirement, if an agent $\mathrm{S}$ decides at time $\mathrm{t}$ to perform action A, and if this action is directly free, then there is a possible world $\mathrm{W}$, with the same laws of nature and the same past up to $t$ as the actual 
world, in which $\mathrm{S}$ decides otherwise at $\mathrm{t}$. The proponent of LO claims that if this is so, then the decision $S$ ultimately makes at $t$ is a matter of luck; and therefore, it cannot be regarded as a free action.

Proponents of LO have put forward various arguments and considerations to support their claim that the L-libertarian's account of a free action is implausible. Thus, for example, Mele argued that, on L-libertarianism, if $\mathrm{A}$ is a directly free action, then the cross-world difference between the actual world and $\mathrm{W}$ with regard to how $\mathrm{S}$ acts at $\mathrm{t}$ has no explanation, and hence is a matter of luck; and that this result commits the L-libertarian to an inconsistency. Levy argued that if there is no explanation of the contrastive fact that $\mathrm{S}$ decided at $\mathrm{t}$ to do $\mathrm{A}$ rather than to do $\mathrm{B}$, where $\mathrm{A}$ and $\mathrm{B}$ have conflicting moral valences, then S's deciding to do A rather than B is a matter of luck, and therefore, $\mathrm{S}$ is not morally responsible for the decision. Van Inwagen introduced the notion of replays, claiming that in some of them $S$ would do otherwise, and that if we could watch enough replays, we would get the impression that what $S$ does at $t$ is a matter of chance. We have considered, in detail, these arguments, as well as others, put forward by the above authors, and have shown that they do not succeed in refuting the L-libertarian claim that agents can, and very often do, exercise enough control over their undetermined actions to be said to have acted freely and responsibly.

What seems to underlie all of these arguments is a resistance, on the part of the proponent of LO, to acknowledge - or a failure sufficiently to appreciate - the very notion of a libertarian free act: that is, the notion of an act's being undetermined and yet under the agent's control. Somehow, the proponent of LO is not willing to acknowledge the idea that the agent can, so to speak, step into the gap left by indetermination and exercise control over what she/he does.

We thus conclude that none of the various versions of LO put forward by Mele, Levy, and van Inwagen, poses a serious threat to L-libertarianism. ${ }^{29}$

\section{Notes}

1. For such an account, see McCann (1998: chap. 8), Ginet (2002), O'Connor (2000: chap. 5), and Goetz (2009: 19-22).

2. Though not all brands of libertarianism share this assumption due to Frankfurt's (1969) criticism of PAP, this seems to be the assumption that is the main target of the Luck Objection.

3. A directly free action is sometimes also referred to as 'a basically free action'. See Mele (2006: chap. 3). 
4. Here we are following McCann's account in his (1998: chap. 8). For other accounts of the relation between reasons and action, see note 1 .

5. Where $\mathrm{A}$ is a free complex action, the agent's causing the intention to A causes further events. For example, S's freely performing the action of flipping the switch, consists in S's agent-causing the intention to flip the switch by moving his thumb (in a certain way), which intention causes the event of his thumb moving, which then causes the event of the switch being flipped. For elegantly developed accounts of ACL, see O'Connor (2000: chap. 4), and Clarke (2003: chaps. 8-10).

6. This position - that reasons indeterministically cause decisions and actions is represented by Kane (1996: 136) and Clarke (2003: chap. 9).

7. This point is important, since the philosophers whose versions of LO we consider devote special attention to trying to debunk ACL, and much of what they say in this regard applies to LL as well.

8. We take this formulation of the notion of a (directly) free action to be equivalent to our formulation of it in terms of LF.

9. Or as Mele (2006: 9) puts it: 'If there is nothing about Joe's powers, capacities, states of mind, moral character, and the like in either world that accounts for this difference, then the difference seems to be just a matter of luck'.

10. This assumption is based on how Mele understands luck. See Mele (2006: 7).

11. It is unclear from Mele's presentation how exactly this step follows from the earlier steps. We try to fill in this gap in the next section.

12. Clarke (2004: sec. 3) claims that Mele could have gone directly from (8) to the conclusion of his argument (12). We disagree with this claim. It seems to rest on the assumption that if a conjunctive fact (i.e., the cross-world difference between the actual world and $\mathrm{W}$ ) is a matter of luck, then each of its conjuncts is a matter of luck, which in turn implies that if $\mathrm{S}$ does not have control over a conjunctive fact, then $\mathrm{S}$ also does not have control over either of its conjuncts. To us this assumption is far from being obvious.

13. Franklin (2011: 220) interprets Mele as moving directly from:

(i) The cross-world difference between the actual world and $\mathrm{W}$ is just a matter of luck, to

(ii) What $\mathrm{S}$ does in both these worlds is partly a matter of luck, and from this to the conclusion that,

(iii) The agent does not act freely in either world.

We think that Franklin's interpretation significantly weakens Mele's argument. Since it is unclear to what extent being partly a matter of luck threatens free agency, it is difficult to see how Mele would be able to infer that in W, the agent does not act freely, and that hence also in the real world he does not act freely.

14. Some critics of Mele - for example, O'Connor (2007) - have interpreted him to be claiming that the reason why the decision $S$ makes in the real world is a matter of luck and hence is not in S's control, is because that decision lacks a contrastive explanation (i.e., an explanation of why in the actual world, $\mathrm{S}$ decides at $t$ to A rather than doing at $t$ something else instead). Mele (2007: 195-8) rejects this interpretation of his position, charging his critics with confusing: (i) the lack of a contrastive explanation of S's behavior at $t$ in the actual world with (ii) the lack of explanation of the cross-world difference 
between the actual world and $\mathrm{W}$ with regard to S's behavior at t. Though Mele does not explicitly support his claim that (i) and (ii) are importantly different, it is not difficult to show that they are - for example, that (ii) does not entail (i). Suppose you are tempted not to keep a lunch appointment with a colleague today. Perhaps you wish today to lunch alone, or perhaps you prefer to continue working during lunch today. However, being (on the whole) a morally conscientious person, you freely decide (at t) to keep the appointment. Now, on the L-libertarian view under discussion, your decision at $\mathrm{t}$ is causally undetermined, and therefore, the cross-world difference between the real world and $\mathrm{W}$ with regard to how you act at $\mathrm{t}$ lacks an explanation. However, your (actual) decision to keep your appointment does not lack a contrastive explanation, since given your moral track record, it was more likely that you would decide to keep it than not.

15. The intermediate steps are these:

From (6a) and (7) we get

(13) Either the decision that $S$ makes at $t$ in the real world is a matter of luck, or the decision $\mathrm{S}$ makes at $\mathrm{t}$ in $\mathrm{W}$ is a matter of luck.

And from (13) and (9) we get

(14) Either S lacks control over the decision he makes at $t$ in the real world, or S lacks control over the decision he makes at $\mathrm{t}$ in $\mathrm{W}$.

Now, it is not the case that $S$ lacks control over the decision he makes at $t$ in the real world. Otherwise, S's decision to A at t wouldn't be a free decision, which would be contrary to assumption (1) of Mele's argument. Hence, we may infer from this and (14) that:

(10) $\mathrm{S}$ lacks control over the decision he makes at $\mathrm{t}$ in $\mathrm{W}$, which means

that in $\mathrm{W}$, that decision cannot be regarded as a directly free action.

16. For a similar diagnosis, see for example, Clarke (2004: sec. 2), Griffith (2010: 47-8), Speak (2011: 32-3), and Franklin (2012: 221).

17. For a forceful reply to Mele that makes the same point from an agent-causal libertarian's perspective, see Clarke (2005: sec. 4).

18. Strictly speaking, Levy argues against ACL, but his objection would apply to LL as well.

19. Levy refers to such an act as 'an action that is uniquely rationalized' (2011: 68).

20. See Introduction.

21. Van Inwagen (2000: 16-17) considers this reply in the form in which an agent-causal libertarian would present it: that is, in terms of agent-causation. However, he argues that appeal to agent-causation does nothing to blunt the force of his argument.

22. The usual bases of probabilistic prediction do not operate on free agents the way they operate in other spheres, according to L-libertarianism. Judgments of the probability that an agent will perform a certain act are usually based on the agent's track record, or how he has acted in the past when he had a similar constellation of reasons. However, extrapolations from past relative frequencies usually presuppose that what has happened and what will happen are, on some level, based on chance; but the L-libertarian holds that free agency is, so to speak, a 'wild card' that can 'trump' extrapolations of 
relative frequencies that are based on chance. A frequency interpretation of probability is appropriate for repeated trials with random outcomes; but it is far from clear that it is appropriate for replays of deliberate actions. This is an important issue, and dealing with it adequately is beyond the scope of this paper.

23. Van Inwagen uses the expression 'I am not able to ...'; we prefer to say that 'it is not in my power to...', or that 'I do not have control over...'. We assume that these three locutions mean the same thing, as far as LO is concerned.

24. For a more developed, more formal presentation of the generalization of [3] and how it conflicts with libertarianism, see van Inwagen (2011: 475-6).

25. In a conversation with van Inwagen (2011: 477).

26. For a more detailed presentation of the generalization of [3a], how it is weaker than the generalization of [3], and how it nevertheless conflicts with something that most libertarians hold, see van Inwagen (2011: 477-80).

27. We may express our point as a dilemma: In the examples, either I am as yet undecided between lying and telling the truth or I am not. If I am, then the examples undermine [1] and [1a]. If I am not, then the examples fail to support [2] and [2a]. Either way the Promising Argument fails.

28. Another puzzling feature of van Inwagen's modified Promising Argument is the following: Van Inwagen seems to assume that it is the fact that it is metaphysically undetermined whether I will do A that renders me not in a position to promise to do A. But we think otherwise. Rather it seems to us that it is really my uncertainty as to whether I will do A that is relevant to rendering me not in a position to promise to do A. That is, if I am uncertain as to whether I will keep my promise, then it makes no difference whether my uncertainty is based on metaphysical indetermination (as libertarians would have it) or is merely epistemic (as determinists would have it) - in either case, I should equally not be in a position to promise to do A. (Consider a modification of van Inwagen's car example: suppose that, instead of its being metaphysically undetermined whether the car will start, I have two identical-looking cars, one which is working and one which isn't; and I don't know which of the two cars I am getting into. I am no more in a position to promise my friend a ride in this case than in the original example of metaphysical indeterminacy.) It is plain common sense that I can never be absolutely certain today that if I promise (today) to do A tomorrow, I will keep my promise. So if van Inwagen is right, then according to everyone - libertarians, compatibilists, and hard determinists alike - no one should ever be in a position to promise anything. Yet presumably van Inwagen does not intend to undermine the institution of promising.

29. We would like to thank Carl Ginet, Carlos Moya, and Rik Peels for helpful comments on an earlier draft of this paper. Earlier versions of the paper were also presented at departmental research seminars at Bar-Ilan University, the University of Utrecht, and the Free University of Amsterdam, in the spring and summer of 2013. We would like to thank the audiences at those presentations for their helpful comments. 